\title{
A New In-Situ Gel Formulation of Itraconazole for Vaginal Administration
}

\author{
Sinem Yaprak Karavana*, Seda Rençber, Zeynep Ay Şenyiğit, Esra Baloğlu \\ Department of Pharmaceutical Technology, Faculty of Pharmacy, Ege University, Bornova, Turkey. \\ Email: *sinem.yaprak.karavana@ege.edu.tr
}

Received August 27 $7^{\text {th }}, 2012$; revised September $30^{\text {th }}, 2012$; accepted October $12^{\text {th }}, 2012$

\begin{abstract}
In this paper, mucoadhesive in-situ gel with poloxamer and hydroxypropylmethylcellulose formulations of itraconazole were prepared for vaginal application. In addition, rheological, mechanical and mucoadhesive properties and syringeability of the formulations were characterized. The mixtures of Poloxamer 407 and 188 with two different types of hydroxypropylmethylcellulose were used as polymers for gel formulations. Flow rheometry studies and oscillatory analysis of each formulation were performed at $20^{\circ} \mathrm{C} \pm 0.1^{\circ} \mathrm{C}$ and $37^{\circ} \mathrm{C} \pm 0.1^{\circ} \mathrm{C}$. All formulations exhibited pseudoplastic flow and typical gel-type mechanical spectra $\left(\mathrm{G}^{\prime}>\mathrm{G}^{\prime \prime}\right)$ after the determined frequency value at $37^{\circ} \mathrm{C}$. Texture profile analysis presented that F3 formulation containing 20\% poloxamer 407, 10\% poloxamer 188 and $0.5 \%$ hydroxypropylmethylcellulose appeared to offer more suitable mechanical and mucoadhesive performance. Using different hydroxypropylmethylcellulose type in formulations didn't significantly change syringeability values. The evaluation of the entire candidate formulations indicated that vaginal formulation of itraconazole will be an alternative for the treatment of vaginal candidiasis with suitable textural and rheological properties. Our results showed that the developed formulations were found worthy of further studies.
\end{abstract}

Keywords: Itraconazole; Poloxamer; Hydroxypropylmethylcellulose; Gel; Vaginal Candidiasis

\section{Introduction}

The azole antifungal agents represent a major advance in the treatment of both superficial and systemic fungal infections. These drugs can be divided in two main groups: the imidazoles and the triazoles [1]. Itraconazole is a broad-spectrum antifungal agent, which can be used either orally or intravenously. However, a vaginal formulation of itraconazole has not been developed yet [24]. It is a safe and effective active substance in the treatment of vulvovaginal candidiasis. It was shown that, active amount of the itraconazole may persist in vaginal epithelium for four days after a one-day treatment. It has been suggested that a cause of relapse in women with vaginal candidiasis is the re-emergence of Candida organisms from deeper layers of vaginal tissue $[5,6]$.

Local drug delivery is frequently utilized for the treatment of localized disorders. The main advantages of this of administration are the ability to deliver the active agent directly to the site and the maintenance of the required concentration of active substance at the site for a prolonged period [7]. For the treatment of vaginitis, local antimicrobial administration of imidazole derivatives has been favored due to the numerous side effects of sys-

${ }^{*}$ Corresponding author. temically applied drugs. To achieve desirable therapeutic effect, vaginal delivery systems need to reside at the sites of infection for a prolonged period [1]. For a long time, a great deal of attention has been devoted to the development of mucoadhesive drug delivery systems. Mucoadhesives may localize in a particular region and prolong the residence time, thereby improve the bioavailability of drugs [8]. Nowadays, in situ-gelling liquids have also proved as more convenient dosage forms for local applications because they are easy to administer into desired body cavities [9]. Poloxamers (Plx) which is chosen to prepare in-situ gel formulation, are synthetic triblock copolymers of poly(ethyleneoxide)-b-poly(propylene oxide)b-poly(ethylene oxide) (PEO-PPO-PEO) that exhibit thermoreversible behaviour in aqueous solutions [10-12]. A change in micellar properties occurs as a function of both environmental temperature and the concentration of Plx and a reversible gelation can occur at physiological temperature $[12,13]$. The use of such systems for local administration of therapeutic agents to the vagina offers several advantages, including ease of application and high spreadability at temperatures below the sol-gel temperature, rheological structuring and hence enhanced retention at body temperature. They have excellent compatibility and good characteristics of prolonged release of 
the active ingredient. On the other hand, they have low mucoadhesive properties.

Hydroxypropylmethylcellulose (HPMC), a well-known cellulose derivative, is generally used to provide sustained release. HPMC is frequently used for mucoadhesive formulations due to its nontoxic, nonirritant, high mucoadhesive characteristics, easy incorporation with the drugs and stability at vaginal $\mathrm{pH}[14,15]$.

It is available in a wide range of molecular weights and is classified by the viscosities of their $2 \%(\mathrm{w} / \mathrm{w})$ aqueous solution [16]. In this study, two types of HPMC were added to improve the mucoadhesive and mechanical properties of in-situ gel formulations.

The objective of this study was to prepare a suitable mucoadhesive in-situ gel formulation of itraconazole with Plx and HPMC that possess appropriate mechanical and rheological properties, retain on the vaginal mucosa for a long period of a time.

\section{Experimental}

\subsection{Materials}

Plx 188 and 407 were kindly gifted by BASF Chemical Company (GERMANY). Itraconazole was selected as a model drug and was obtained from Nobel Pharmaceutical Company (TURKEY). HPMC E50 (40 - 60 cps) and K100M (80 - $120 \mathrm{cps)}$ were donated by Colorcon (ENGLAND). All other materials were of analytical grade.

\subsection{Preparation of Formulations}

Vaginal mucoadhesive gel formulations of itraconazole was prepared with $20 \% \mathrm{Plx}$ 407:10\% Plx 188 mixture; and adding either $0.5 \%$ HPMC E50 or $0.5 \%$ HPMC $\mathrm{K} 100 \mathrm{M}$ as mucoadhesive agent. Plx mixture ratio was decided according to our previous study [6]. Gels were prepared by a modification of the cold method [17]. Distilled water was cooled to $4^{\circ} \mathrm{C}$. Plx 188 and 407 were then slowly added to the distilled water with continuous agitation. The gels were left at $4{ }^{\circ} \mathrm{C}$ until a clear solution was obtained. Then, $0.5 \%$ HPMC K100M or HPMC E50 were gradually added and these gels were left at room temperature for 24 hours. Finally, $2 \%$ itraconazole was added with vigorous stirring. The compositions of gels are given in Table 1.

\subsection{Determination of $\mathbf{p H}$}

To investigate the compatibility of the gel bases for vaginal application, their $\mathrm{pH}$ values were measured by a $\mathrm{pH}$ meter (NEL Mod.821) at room temperature $(\mathrm{n}=5)$.

\subsection{Measurement of Gelation Temperature and Gelation Time}

Determination of gelation temperature and gelation time were carried out on Haake Mars rheometer and were determined graphically. The geometry was a stainless steal plate/plate (diameter $40 \mathrm{~mm}$ ), which provided a homogeneous shear of the sample. The sol-gel transition temperatures and gelation times of the gels were determined from oscillation measurements with a fixed frequency of $0.01 \mathrm{~Hz}$. The samples were heated at a rate of $2^{\circ} \mathrm{C}$ every $60 \mathrm{~s}$, the temperature changed between $7^{\circ} \mathrm{C}$ $70^{\circ} \mathrm{C}$ during the procedure $(\mathrm{n}=5)$. The sol-gel transition temperature graph was determined by plotting temperature as a function of the viscosity $\left(\eta^{\prime}\right)$ and the transition point was defined as the point where the viscosity was halfway between the values for the solution and the gel [6].

\subsection{Mechanical Properties of Polymer Solutions}

Textural analysis was performed using Software-controlled penetrometer [TA-TX Plus, Stable Micro System, UK] equipped with $5 \mathrm{~kg}$ load cell in Texture Profile Analysis (TPA) mode. Formulations were transferred into jacketed glass vial $(20 \mathrm{~mL})$ at $20^{\circ} \mathrm{C}$ and $37^{\circ} \mathrm{C}$. In this, an analytical probe was twice compressed into each formulation to a defined depth $(15 \mathrm{~mm})$ and at a defined rate $(2 \mathrm{~mm} / \mathrm{s})$, allowing a delay period $(15 \mathrm{~s})$ between the end of the first and beginning of the second compression. Mechanical parameters (hardness, compressibility, adhesiveness, cohesiveness and elasticity) were derived and calculated from the resultant force-time curve [18]. Experiments were carried out at least three times. From the resultant force-time plots, several mechanical parameters may be derived [19]. These include:

- hardness (the force required to attain a given deformation)

Table 1. The composition of formulations.

\begin{tabular}{ccccccc}
\hline Codes of formulation & Plx 407 (\%) & PIx 188 (\%) & HPMC K100M (\%) & HPMC E50 (\%) & Itraconazole (\%) & Distilled water (\%) \\
\hline F1 & 20 & 10 & 0.5 & - & - & 69.5 \\
F2 & 20 & 10 & - & 0.5 & - & 69.5 \\
F3 & 20 & 10 & 0.5 & 0.5 & 2 & 67.5 \\
F4 & 20 & 10 & - & 2 & 67.5 \\
\hline
\end{tabular}


- compressibility (the work required to deform the sample during the first compression of the probe)

- adhesiveness (the work required to overcome the attractive forces between the surface of the sample and the surface of the probe)

- cohesiveness (the ratio of the area under the forcetime curve produced on the second compression cycle to that on the first compression cycle, where successive compressions are separated by a defined recovery period)

- elasticity (the rate at which the deformed sample returns to its undeformed condition after the removal of the deforming force)

\subsection{Evaluation of the Mucoadhesive Properties}

The mucoadhesive strength of the formulations was evaluated by measuring the force required to detach the formulation from a mucin disc using a $5 \mathrm{~kg}$ load cell TPA in tension mode $[18,20]$. Mucin discs $(250 \mathrm{mg})$ were hydrated with $50 \mu \mathrm{L}$ mucin solution before the experiment and they were attached to the lower end of the probe (P 10 Perspex, $\theta: 10 \mathrm{~mm}$ ). The gels were packed into the beaker. The probe holding the mucin disc was lowered on to the surface of the gel with a constant speed of $0.1 \mathrm{~mm} \cdot \mathrm{s}^{-1}$ and a contact force of $0.05 \mathrm{~N}$ were applied. After keeping in contact surfaces for $120 \mathrm{~s}$, the probe was then moved vertically upward at a constant speed of 0.1 $\mathrm{mm} \cdot \mathrm{s}^{-1}$. Maximum detachment force $(\mathrm{F})$ was obtained from the force-distance graph. The area under the curve (AUC) was calculated from force-distance plot as the mucoadhesion (M). The tests were conducted at $37^{\circ} \mathrm{C}$ and each experiment was carried out five times.

\subsection{Syringeability of the Formulations}

The syringeability of the formulations was examined using a software controlled penetrometer in compression mode. A filled $2 \mathrm{~mL}$ syringe was held in place with a clamp and the upper probe of the texture analyzer moved downwards until it came in contact with the syringe barrel base. A constant force of $0.5 \mathrm{~N}$ was applied to the base and the work required to expel the contents for a barrel length of $30 \mathrm{~mm}$ was measured. The area under the resulting curve was used to determine the work of expulsion ([22]). The tests were conducted at room temperature and each experiment was carried out five times. The syringeability device is described in Figure 1.

\subsection{Rhelogical Studies}

All the formulations were characterized rheologically using Haake Mars rheometer. Continuous shear analysis of each formulation was performed at $20^{\circ} \mathrm{C} \pm 0.1^{\circ} \mathrm{C}$ and $37^{\circ} \mathrm{C} \pm 0.1^{\circ} \mathrm{C}$, in flow mode, and in conjunction with parallel steel plate geometry (diameter $40 \mathrm{~mm}$ ) and gap

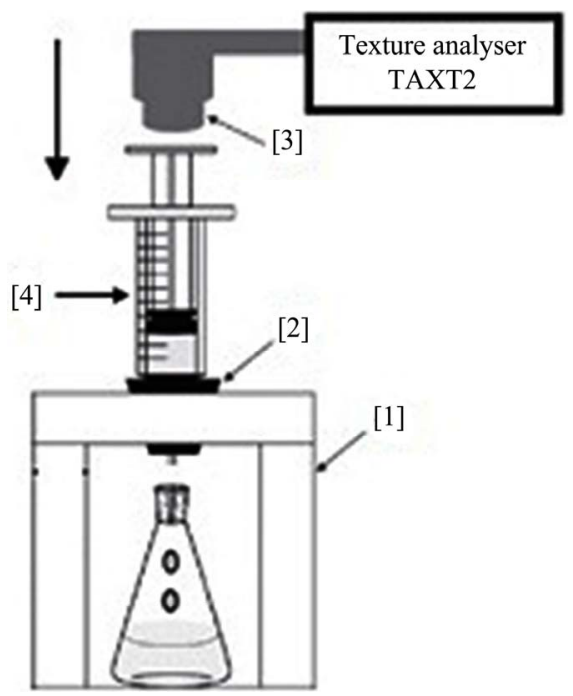

Figure 1. Experimental set-up for the measurement of the syringeability force developed during injection: 1) metallic support; 2) plastic clamping ring; 3) force transducer and 4) syringe (adapted from reference [22]).

of $0.3 \mathrm{~mm}$. Samples were carefully applied to the lower plate of enstrument, ensuring that formulation shearing was minimized and allowed to equilibrate for at least 1 min prior to analysis. Upward and downward flow curves were measured over a range of shear rates $\left(10-1000 \mathrm{~s}^{-1}\right)$. The flow properties of at least five replicate samples were determined $[23,24]$.

Oscillatory analysis of each formulation under examination was performed after determination of its linear viscoelastic region at $20^{\circ} \mathrm{C} \pm 0.1^{\circ} \mathrm{C}$ and $37^{\circ} \mathrm{C} \pm 0.1^{\circ} \mathrm{C}$, where stress was directly proportional to strain and the storage modulus remained constant. Frequency sweep analysis was performed over the frequency range of 0.1 $10 \mathrm{~Hz}$ following application of a constant stress and standard gap size was $0.3 \mathrm{~mm}$ for each sample. Storage modulus $\left(\mathrm{G}^{\prime}\right)$ and loss modulus $\left(\mathrm{G}^{\prime \prime}\right)$, the dynamic viscosity $\left(\eta^{\prime}\right)$, and the loss tangent $(\tan \delta)$ were determined. In each case, the dynamic rheological properties of at least five replicates were examined $[25,26]$.

\subsection{Statistical Data Analysis}

Statistical data analysis was performed using the Student $t$-test with $P<0.05$ as the minimal level of significance.

\section{Results}

The gelation temperatures of the F1, F2, F3 and F4 formulations were found to be $34.47^{\circ} \mathrm{C} \pm 0.03^{\circ} \mathrm{C}, 34.47^{\circ} \mathrm{C} \pm$ $0.02^{\circ} \mathrm{C}, 34.47^{\circ} \mathrm{C} \pm 0.02^{\circ} \mathrm{C}$ and $34.46^{\circ} \mathrm{C} \pm 0.03^{\circ} \mathrm{C}$, respectively. Gelation time is also an important parameter for determining vaginal retention of formulation [21]. For our formulations these value were between $326.63 \pm 0.35$ sec and $326.98 \pm 0.17 \mathrm{sec}$. The $\mathrm{pH}$ values of the F1, F2, 
F3 and F4 formulations were found to be $6.52 \pm 0.06$, $7.25 \pm 0.07,6.95 \pm 0.04$ and $7.01 \pm 0.04$, respectively. The TPA graphs of formulations at $37^{\circ} \mathrm{C}$ are presented in Figure 2 and the mechanical properties of formulations are presented in Table 2.

Mucoadhesive formulations have been reported to prolong the residence time of the formulation at the site of application [6]. Mucoadhesive studies were carried out only at body temperature because the formulations were in liquid form at room temperature. In this study the work of adhesion was used to quantify adhesion. This measure provides a more comprehensive evaluation of the detachment phenomenon [27]. The related data of the detachment force, mucoadhesion and work of adhesion of the formulations are listed in Table 3. The syringeability of each formulation is also presented in Table 3.

Representative flow curves of in-situ gel formulations were graphically presented in Figure 3.

Oscillatory analysis was also carried out at both room and body temperature. Thereby, the changes of the struc-

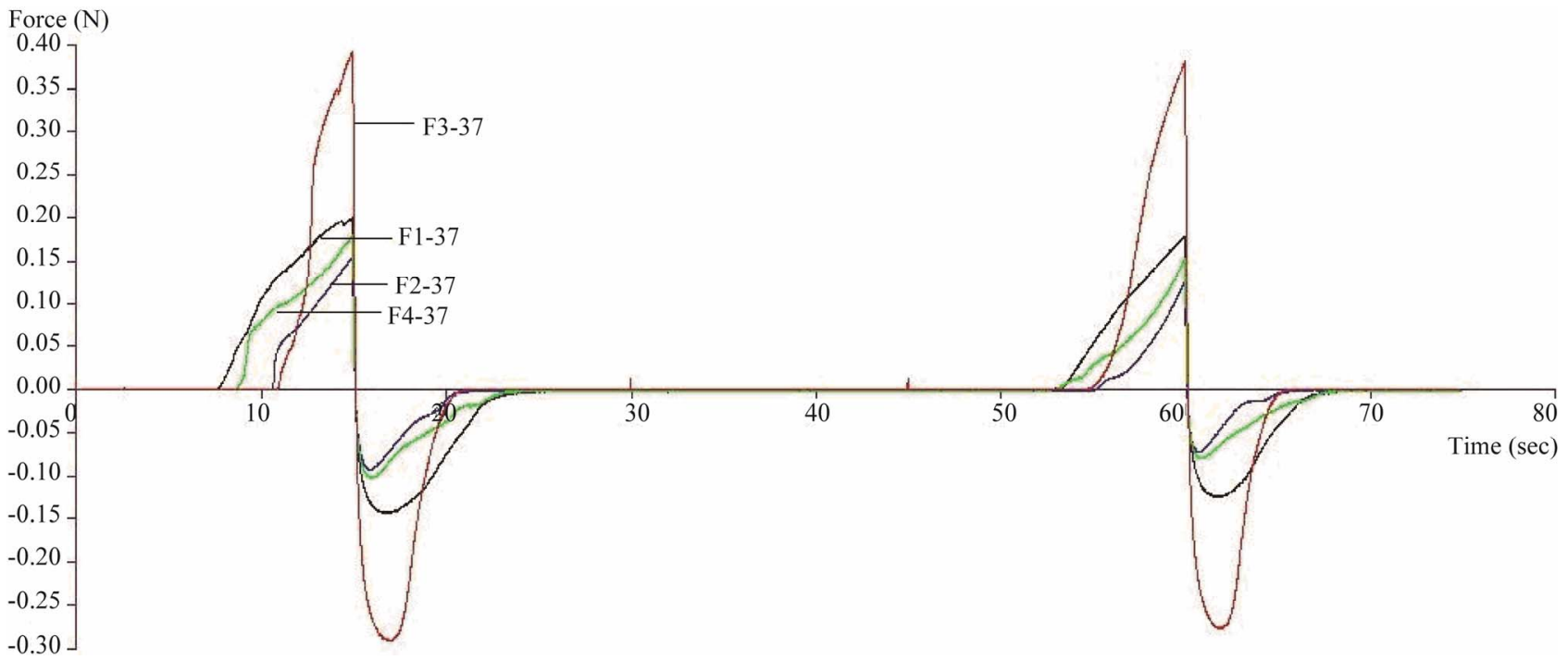

Figure 2. TPA analysis graphs of F1, F2, F3 and F4 at $37^{\circ} \mathrm{C}$.

Table 2. Mechanical properties of formulations.

\begin{tabular}{cccccc}
\hline Codes & $\mathbf{H}(\mathbf{N}) \pm \mathbf{S D}$ & $\mathbf{C}(\mathbf{N} . \mathbf{m m}) \pm \mathbf{S D}$ & $\mathbf{A}(\mathbf{N} . \mathbf{m m}) \pm \mathbf{S D}$ & $\mathbf{E} \pm \mathbf{S D}$ & $\mathbf{C h} \pm \mathbf{S D}$ \\
\hline $\mathbf{F 1 - 2 0}{ }^{\circ} \mathbf{C}$ & $0.016 \pm 0.003$ & $0.103 \pm 0.037$ & $0.036 \pm 0.006$ & $0.931 \pm 0.047$ & $0.915 \pm 0.009$ \\
$\mathbf{F} 1-37^{\circ} \mathbf{C}$ & $0.196 \pm 0.011$ & $0.779 \pm 0.030$ & $0.662 \pm 0.026$ & $1.102 \pm 0.137$ & $0.725 \pm 0.041$ \\
$\mathbf{F 2 - 2 0}^{\circ} \mathbf{C}$ & $0.017 \pm 0.003$ & $0.125 \pm 0.058$ & $0.039 \pm 0.006$ & $0.954 \pm 0.066$ & $0.889 \pm 0.012$ \\
$\mathbf{F 2 - 3 7}^{\circ} \mathbf{C}$ & $0.156 \pm 0.009$ & $0.426 \pm 0.048$ & $0.38 \pm 0.029$ & $1.097 \pm 0.025$ & $0.572 \pm 0.007$ \\
$\mathbf{F 3 - 2 0}^{\circ} \mathbf{C}$ & $0.009 \pm 0.002$ & $0.021 \pm 0.001$ & $0.035 \pm 0.000$ & $0.944 \pm 0.036$ & $0.864 \pm 0.069$ \\
$\mathbf{F 3 - 3 7}^{\circ} \mathbf{C}$ & $0.394 \pm 0.053$ & $0.900 \pm 0.026$ & $0.961 \pm 0.018$ & $1.713 \pm 0.447$ & $1.050 \pm 0.095$ \\
$\mathbf{F 4 - 2 0}^{\circ} \mathbf{C}$ & $0.007 \pm 0.000$ & $0.011 \pm 0.0001$ & $0.028 \pm 0.004$ & $0.823 \pm 0.050$ & $0.751 \pm 0.057$ \\
$\mathbf{F 4 - 3 7}^{\circ} \mathbf{C}$ & $0.131 \pm 0.003$ & $0.762 \pm 0.013$ & $0.579 \pm 0.021$ & $0.993 \pm 0.107$ & $0.714 \pm 0.152$ \\
\hline
\end{tabular}

*H: Hardness, C: Compressibility, A: Adhesiveness, E: Elasticity, Ch: Cohesiveness.

Table 3. Results of mucoadhesion studies of the formulations with mucin disc and syringeability studies.

\begin{tabular}{ccccc}
\hline Codes & F (N) \pm SD & M $(\mathbf{m J}) \pm \mathbf{S D}$ & $\mathbf{W}\left(\mathbf{m J} / \mathbf{c m}^{2}\right) \pm \mathbf{S D}$ & Syringeability $(\mathbf{N . s n}) \pm \mathbf{S D}$ \\
\hline F1 & $0.151 \pm 0.035$ & $0.077 \pm 0.056$ & $0.094 \pm 0.068$ & $11.130 \pm 1.986$ \\
$\mathbf{F 2}$ & $0.215 \pm 0.052$ & $0.082 \pm 0.040$ & $0.100 \pm 0.048$ & $13.663 \pm 2.893$ \\
F3 & $0.230 \pm 0.067$ & $0.064 \pm 0.037$ & $0.078 \pm 0.045$ & $16.425 \pm 2.065$ \\
F4 & $0.163 \pm 0.046$ & $0.042 \pm 0.011$ & $0.051 \pm 0.013$ & $16.900 \pm 2.788$ \\
\hline
\end{tabular}

*F: Detachment force, M: Mucoadhesion, W: Work of adhesion. 
cture of the formulation were investigated in both temperatures. Figure 4 shows the rheological properties of the formulations.

In Table 4 and Figure 5, effect of temperature on the loss tangent and dynamic viscosity of formulation at certain frequencies were presented.

\section{Discussion}

Poloxamer molecules in solution exhibit a zigzag configuration, initially transforming into a close-packed configuration and then to a viscous gel due to the increasing temperature [28]. Sol-gel transition temperature is the temperature at which the liquid phase makes transition into a gel. The transformation from the solution to the form after the application is important for efficient therapy due to the covering mucosal tissue and the decreasing the vaginal leakage. Ideally the gelation temperature of mucosal formulations should be $30^{\circ} \mathrm{C}-36^{\circ} \mathrm{C}[11,17,29]$. If the gelation temperature is high, the formulation exhibits liquid properties at physiological temperatures and leakage results. Conversely, lower gelation temperatures may result in problems concerning application due to the viscous nature of the formulation. It is known that the sol-gel transition temperature can be changed by addition of the active substance or additivies [30]. But for our formulations, addition of active substance didn't affect gelation temperatures. Gelation temperatures of our formulations were found suitable for the vaginal

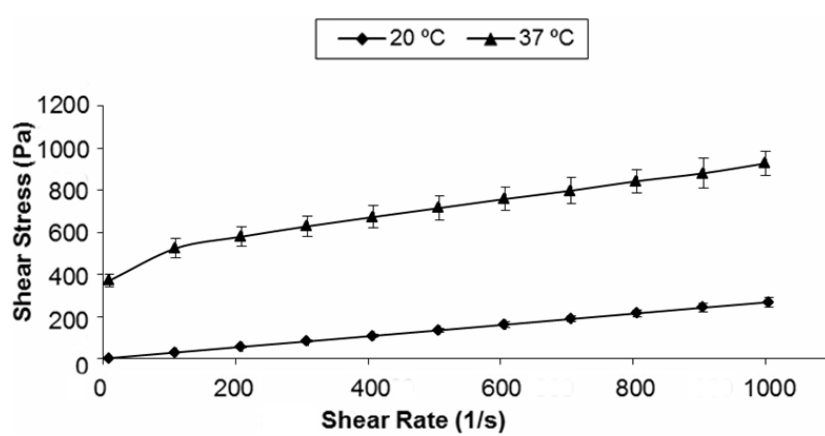

F1

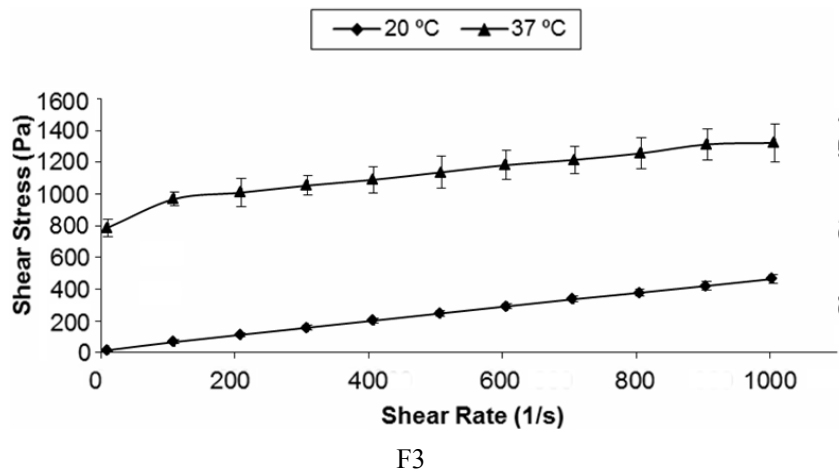

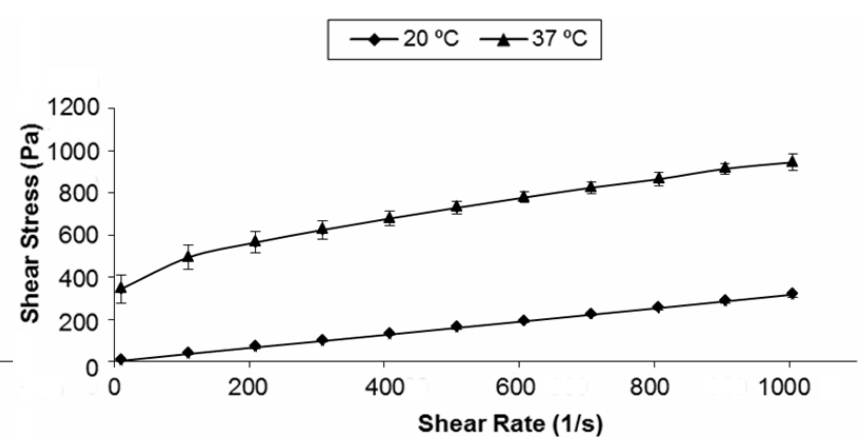

F2

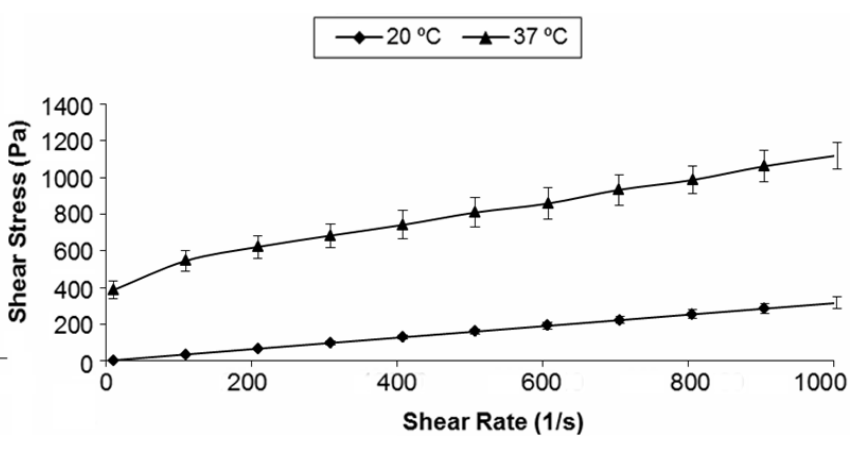

F4

Figure 3. Flow curves of itraconazole formulations at $20^{\circ} \mathrm{C}$ and $37^{\circ} \mathrm{C}$.

Table 4. Effect of temperature on the dynamic viscosity $\left(\eta^{\prime}\right)$ of formulations at five representative frequencies.

\begin{tabular}{ccccccc}
\hline \multirow{2}{*}{ Codes of Formulations } & Temperature $\left({ }^{\circ} \mathbf{C}\right)$ & \multicolumn{5}{c}{$\boldsymbol{\eta}^{*}$ (Pa.s) values at different ossilasion frequency } \\
\cline { 3 - 7 } & & $\mathbf{0 . 6 0 ~ H z}$ & $\mathbf{2 ~ H z}$ & $\mathbf{5 ~ H z}$ & $\mathbf{7 ~ H z}$ & $\mathbf{1 0 ~ H z}$ \\
\hline \multirow{2}{*}{$\mathbf{F 1}$} & $\mathbf{2 0}$ & $14.481 \pm 0.880$ & $3.465 \pm 0.764$ & $1.482 \pm 0.659$ & $1.338 \pm 0.538$ & $1.152 \pm 0.494$ \\
& $\mathbf{3 7}$ & $679.625 \pm 0.500$ & $213.800 \pm 0.431$ & $92.988 \pm 0.324$ & $67.330 \pm 0.510$ & $50.143 \pm 0.402$ \\
\multirow{2}{*}{$\mathbf{F 2}$} & $\mathbf{2 0}$ & $10.433 \pm 0.235$ & $2.886 \pm 0.12$ & $1.288 \pm 0.096$ & $0.925 \pm 0.023$ & $0.601 \pm 0.052$ \\
& $\mathbf{3 7}$ & $471.300 \pm 0.654$ & $203.267 \pm 0.235$ & $101.093 \pm 0.365$ & $77.237 \pm 0.652$ & $58.403 \pm 0.265$ \\
\multirow{2}{*}{$\mathbf{F 3}$} & $\mathbf{2 0}$ & $30.347 \pm 0.485$ & $5.158 \pm 0.251$ & $4.335 \pm 0.159$ & $1.674 \pm 0.571$ & $2.049 \pm 0.485$ \\
& $\mathbf{3 7}$ & $804.850 \pm 0.396$ & $126.743 \pm 0.254$ & $44.638 \pm 0.158$ & $17.790 \pm 0.654$ & $14.264 \pm 0.478$ \\
& $\mathbf{F 4}$ & $10.415 \pm 0.096$ & $3.907 \pm 0.098$ & $2.010 \pm 0.065$ & $1.009 \pm 0.030$ & $0.917 \pm 0.002$ \\
& $\mathbf{2 0}$ & $1005.600 \pm 0.216$ & $299.300 \pm 0.365$ & $117.650 \pm 0.652$ & $79.205 \pm 0.521$ & $47.640 \pm 0.321$ \\
\hline
\end{tabular}




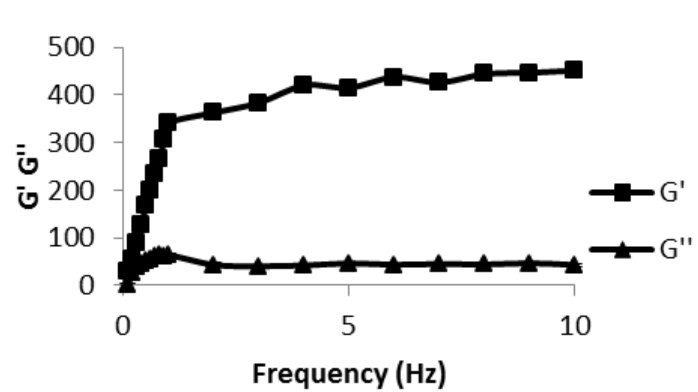

$\mathrm{F} 1\left(20^{\circ} \mathrm{C}\right)$

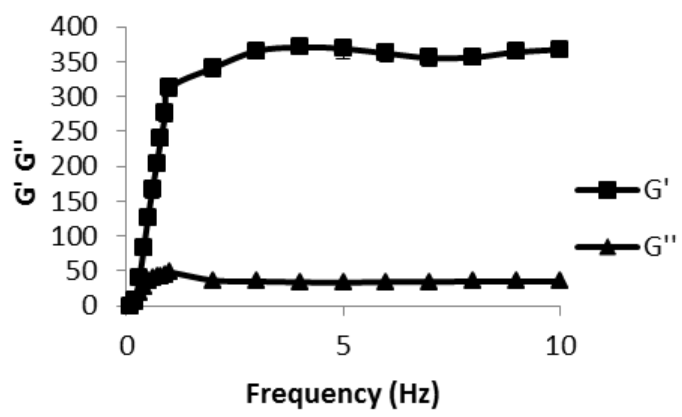

$\mathrm{F} 2\left(20^{\circ} \mathrm{C}\right)$

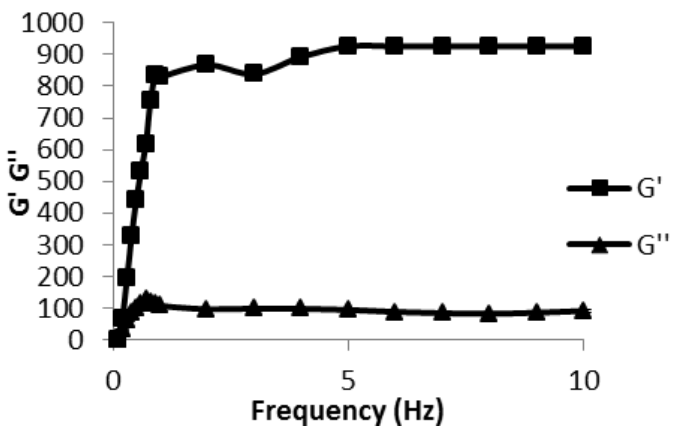

$\mathrm{F} 3\left(20^{\circ} \mathrm{C}\right)$

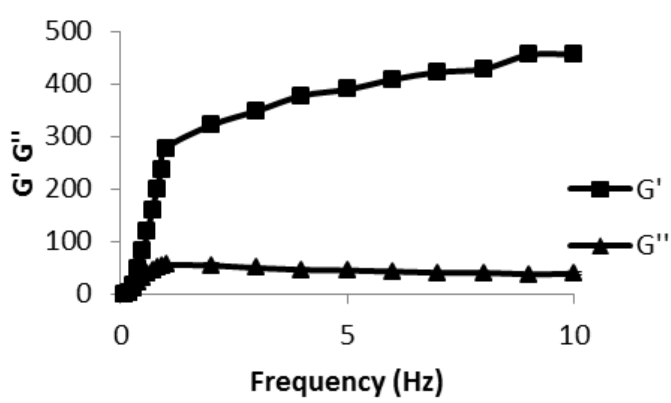

F4 $\left(20^{\circ} \mathrm{C}\right)$

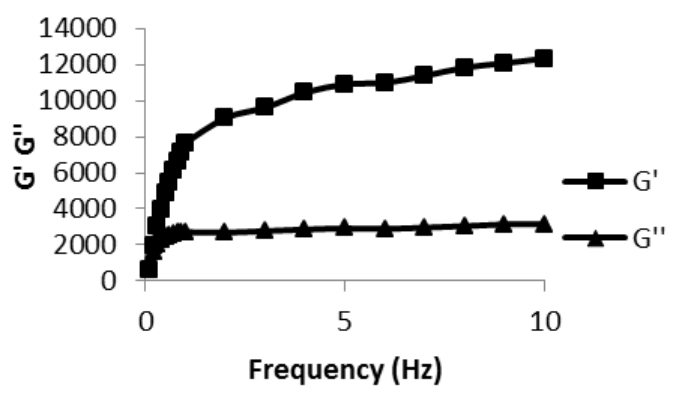

$\mathrm{F} 1\left(37^{\circ} \mathrm{C}\right)$

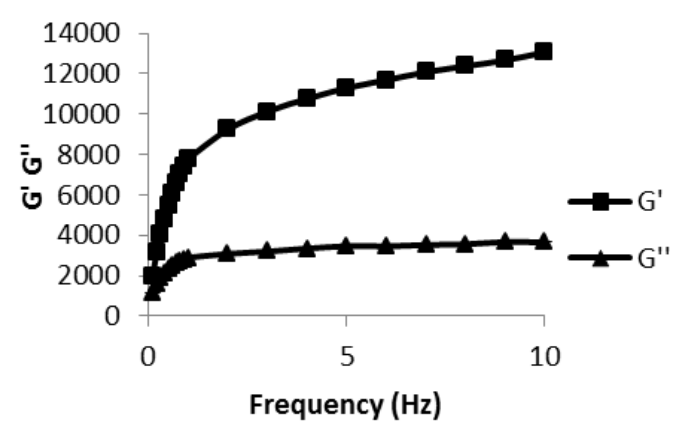

$\mathrm{F} 2\left(37^{\circ} \mathrm{C}\right)$

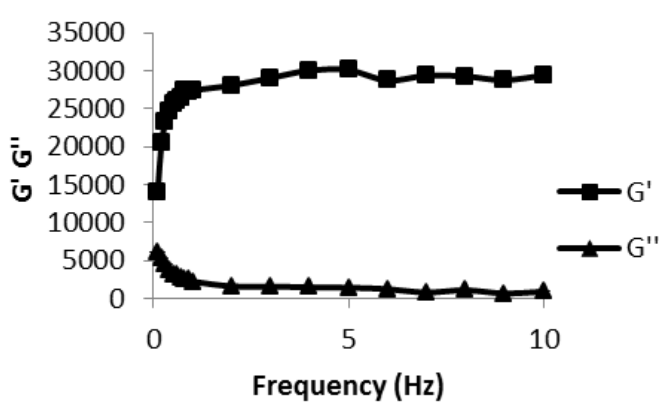

$\mathrm{F} 3\left(37^{\circ} \mathrm{C}\right)$

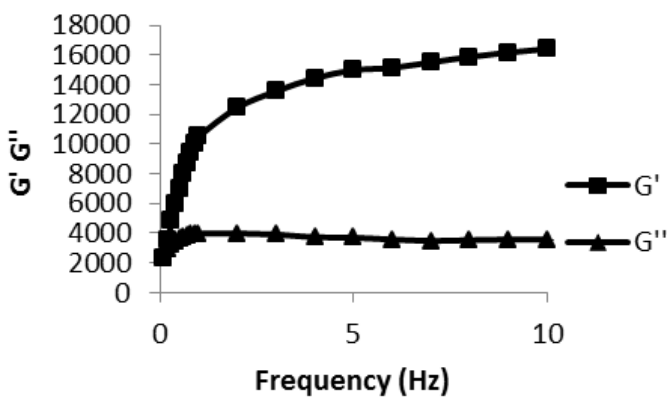

$\mathrm{F} 4\left(37^{\circ} \mathrm{C}\right)$

Figure 4. Frequency-dependent changes of viscoelastic properties of the formulations.

application. Our formulations behaved as viscous liquid at room temperature and transformed to gel at body temperature. So, their application will be easy with a catheter and increased viscosity could be a solution of leakage.

Most of the studies which used Plx as a polymer have focused only on rheological properties, and sustained release action of thermosensitive hydrogels. There is a lack of knowledge on practical administration of formulation to the body such as syringeability and gelation time. But, these two factors are crucial in the develop- 

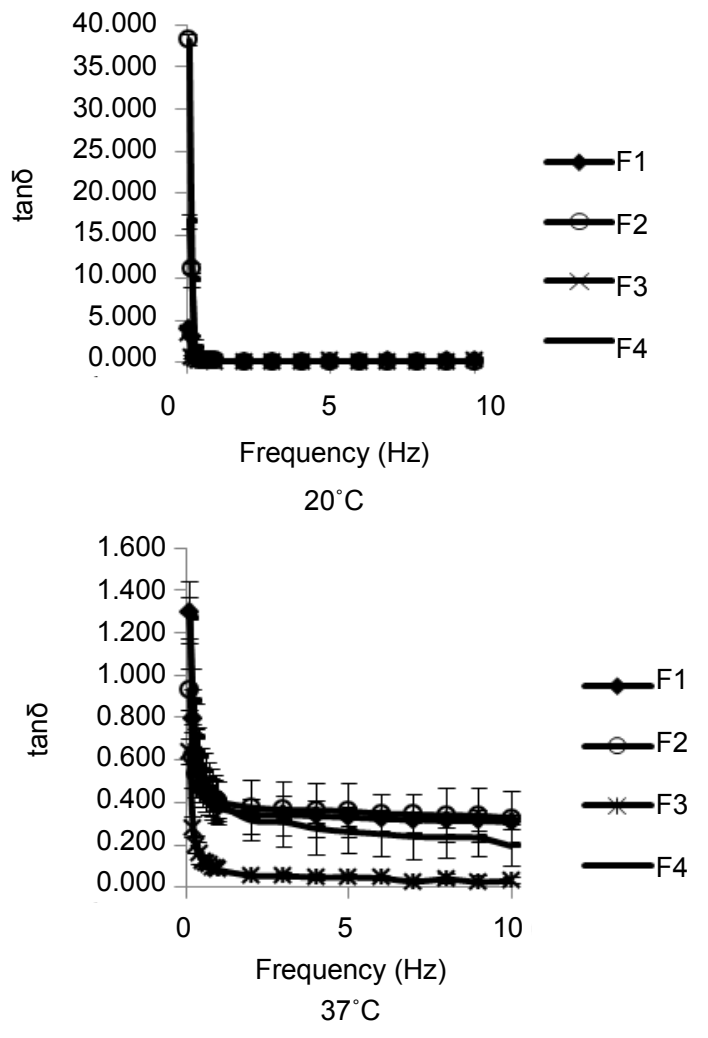

Figure 5. Frequency-dependent changes of loss tangent $(\tan \delta)$ of the formulations.

ment of a desirable thermosensitive hydrogel that is easy to administer to the body and gels rapidly, enabling practical use in pharmaceutical preparations [31]. Because of this reason, we examined these two parameters of formulation with other properties. The determination of the gelation time of a gel formulation requires a knowledge of the viscosity of the solution as a function of time. The short gelation time was advantageous to prevent the drainage from the site of application leading to a prolonged retention of the active substance on the mucosal tissue [32]. In our previous studies, we know that the formulations include Plx alone has short gelation times [7]. Adding HPMC to the formulations caused increased gelation time of the formulations. However, gelation time values were still suitable for vaginal applications.

The $\mathrm{pH}$ values of the prepared formulations were found in physiological limitations and they were deemed to be suitable for vaginal administration.

TPA is a mechanical test that describes the resistance of pharmaceutical formulations to compressive stresses and subsequent relaxation. The parameters derived from this technique (hardness, compressibility, adhesiveness, elasticty and cohesiveness) have been proven to be relevant to the performance of local formulations, e.g. ease of removal from the container, ease of application to the surface and retention of the product at the site of application.
For this reason, TPA is frequently used to identify formulations that may be suitable for clinical application [22]. Hardness and compressibility describe the stress/ work required to remove the sample from the container and to subsequently apply this to the site of application. These characteristics quantify sample deformation under compression and should be low to allow the gel to be easily removed from the container and spread onto the mucosal epithelia. The hardness and compressibility values of the gels increased significantly due to the increases in polymer concentration. Adhesiveness, a property related to mucoadhesion, is defined as the work required to detach probe from the sample in which its cohesive bonds were broken and describes the relative properties of each candidate formulation. Product elasticity represents the rate at which the deformed sample returns to its undeformed condition. Lower numerical values as determined by TPA in the elasticity mode indicate greater product elasticity [33]. TPA also provides information on the effects of repeated shearing stresses on the structural properties of formulations, a property termed its "cohesiveness" [34-36]. As it can be seen from the Table 2, compressibility, adhesiveness and cohesiveness values of the gels not significantly increased with addition of active substance. The gel structure of F3, containing $0.5 \%$ HPMC K100M and itraconazole $2 \%$, exhibited the greatest compressibility, adhesiveness and cohesiveness. Based on these properties, F3 appeared to offer more suitable performance than other formulations.

The contact time of a formulation on the mucosa is of high importance for vaginal drug delivery. Mucoadhesive formulations have been reported to prolong the residence time of the formulation at the site of application. Quantification of mucoadhesion is important to ensure that the adhesion offered by formulations is sufficient to ensure prolonged retention at the site of application [37]. Importantly, the formulations under examination displayed significant mucoadhesion, similar to other systems that have been used for implantation into body cavities. It is known that HPMC exhibits a mucoadhesive property. Although Plx is not as mucoadhesive as HPMC, its solgel transition ability increases the viscosity of the solution at physiological temperature. Hence, combinations of HPMC and Plx showed higher mucoadhesiveness at $37^{\circ} \mathrm{C}$. Using two different viscosity type of HPMC did not significantly effect the mucoadhesive properties of the formulations. Also, our experimental datas indicated that $\mathrm{F} 3$ formulation has higher mucoadhesive properties than other formulations. Result of mucoadhesive studies showed similarity with TPA analysis.

Syringeability of the in-situ gel formulations presented the effect that content of the formulation have on the force required to expel the product. Although, our formulations viscous liquid at $20^{\circ} \mathrm{C}$, syringeability is still 
important parameter to show easy application of our formulations. According to the result our study, addition of active substance did not significantly affect syringeability of formulations. On the other hand, using different HPMC polymer types in formulation did not significantly change syringeability values of formulations.

The evaluation of the rheological properties for the gel type dosage forms would be important for predicting their behavior in vivo. The shear stress changes upon shear rates have been used to determine whether the rheological behavior of the formulation is Newtonian or non-Newtonian. Non-newtonian flow is typical for poloxamer formulations at higher temperatures than sol-gel transition temperature [18]. In continuous shear rheometry, all formulations exhibited pseudo-plastic flow at $37^{\circ} \mathrm{C}$ as it was expected due to its thermoresponsive property. Our results showed similarity with the literature [6,21]. Among the all formulations, high shear stress values were obtained with F3 formulation.

The rheological properties of in-situ gel formulations affect both the ease of application and retention within the vagina. Following local application to the vagina, it is accepted that the equilibrium rheological properties of the formulations will dominate the subsequent physicochemical properties. In polymer solutions, at a sufficiently high concentration, there are entanglements among the polymer chains but there is sufficient time for polymer chains to distangle and flow during a single oscillation at low frequencies $\left(G^{\prime \prime}>G^{\prime}\right)$. Conversely, as the elastic properties of the sample increase, interchain entanglements do not have sufficient time to come apart within the period of single oscillation and $\mathrm{G}^{\prime}$ becomes higher than $\mathrm{G}^{\prime \prime}[34$, 38]. A gel should exhibit a solid-like mechanical spectrum, that is, $\mathrm{G}^{\prime}>\mathrm{G}^{\prime \prime}$ throughout the experimentally accessible frequency range, and there should be little frequency dependence of the moduli [39].

In oscillatory rheometry the effects of oscillatory stresses on the viscoelastic properties are measured, from which two dynamic moduli, namely, the storage modulus, $\mathrm{G}^{\prime}$, a measure of the elasticity, and the loss modulus, $\mathrm{G}^{\prime \prime}$, representing viscous components at a given frequency of oscillation, are obtained [20,21]. Frequency-independent behaviour presents a gel like material whereas the frequency dependence shows the viscous fluid. According to the results, F3 formulations were found nearly frequency independent after certain frequency values and this formulation exhibited typical gel-type mechanical spectra $\left(\mathrm{G}^{\prime}>\mathrm{G}^{\prime \prime}\right)$ at $37^{\circ} \mathrm{C}$. It was also investigated that presence of itraconazole and HPMC K100M provided higher elasticity value for $\mathrm{F} 3$ formulation comparing to other formulations. Greater elasticity of this formulation would be expected to enhance retention at the site of application.

The value of phase angle $\left(\tan \delta=\mathrm{G}^{\prime \prime} / \mathrm{G}^{\prime}\right)$, which is a measure of the relative contribution of viscous components to the mechanical properties of the materials, was $<1$ for all of the formulations at $37^{\circ} \mathrm{C}$ (solid gel response) but was $>1$ for all of the formulations at $20^{\circ} \mathrm{C}$ (liquid-like response). Thus, as $\tan \delta$ becomes smaller, the elasticity of the formulation increases, while the viscous behavior is reduced. As it was expected, $\tan \delta$ values were found higher for all the formulations at $20^{\circ} \mathrm{C}$ than $37^{\circ} \mathrm{C}$ [20]. F4 formulation showed more elastic property than other formulations and this result is accordance with TPA analysis.

Dynamic viscosity $\left(\eta^{\prime}\right)$ is described as the flow resistance of the sample in the structure state, originating as viscous or elastic flow resistance to oscillating movement. The higher value of dynamic viscosity means the greater the resistance to flow in the structured state [20]. In our study, the highest $\eta^{\prime}$ was obtained with F4 formulation due to its more consistent gel structure. The observed large dynamic viscosities of gels at low oscillatory frequencies are characteristic of viscoelastic systems.

\section{Conclusion}

This study has described the in-situ gel formulations of itraconazole and evaluated their textural and rheological properties. Plx has low mucoadhesive properties but its termal sensitivity lead to easy application and covering over the mucosa. Adding HPMC to the formulation decreased the sol-gel transition temperature, and affected the mucoadhesive, mechanical and rheological properties of the formulation. The results showed that the texture characterization was in agreement with rheological results confirming the improved mechanical properties of PlxHPMC formulations. As a result, the evaluation of the entire candidate formulations indicated that vaginal formulation of itraconazole will be a new alternative for the treatment of vaginal candidiasis with suitable textural and rheological properties. Our results showed that the developed formulations were found worthy of further studies.

\section{REFERENCES}

[1] K. Six, T. Daems, J. Hoon, A. V. Hecken, M. Depre, M. P. Bouche, P. Prinsen, G. Verreck, J. Peeters, M. E. Brewster and G. V. Mooter, "Clinical Study of Solid Dispersions of İtraconazole Prepared by Hot-Stage Extrusion," European Journal of Pharmaceutical Sciences, Vol. 24, No. 2-3, 2005, pp. 179-186. doi:10.1016/j.ejps.2004.10.005

[2] S. Grant and S. Clissold, "Itraconazole: A Review of Its Pharmacodynamic and Pharmacokinetic Properties and Therapeutic Use in Superficial and Systemicmycoses," Drugs, Vol. 37, No. 3, 1989, pp. 310-344. doi:10.2165/00003495-198937030-00003

[3] Y. Yi, H. J. Yoon, B. O. Kim, M. Shim, S. O. Kim, S. J. 
Hwang and M. H. Seo, "A Mixed Polymeric Miceller Formulation of İtraconazole: Characteristics, Toxicity and Pharmacokinetics," Journal of Controlled Release, Vol. 117, No. 1, 2007, pp. 59-67.

doi:10.1016/i.jconrel.2006.10.001

[4] F. C. Odds, "Itraconazole-A New Oral Antifungal Agent with a Very Broad Spectrum of Activity in Superficial and Systemic Mycoses," Journal of Dermatological Science, Vol. 5, No. 2, 1993, pp. 65-72. doi:10.1016/0923-1811(93)90072-W

[5] A. K. Gupta and R. Bluhm, "Itraconazole (Sporanox) for Vulvovaginal Candidiasis," Skin Therapy Letter, Vol. 7, Suppl. 1, 2002, pp. 1-3.

[6] G. E. Stein and N. Mummaw, "Placebo-Controlled Trial of Itraconazole for Treatment of Acute Vaginal Candidiasis. Antimicrobial Agents and Chemotherapy, Vol. 37, No. 1, 1993, pp. 89-92. doi:10.1128/AAC.37.1.89

[7] E. Baloglu, S. Y. Karavana, Z. Ay Senyigit and T. Guneri, "Rheological and Mechanical Properties of Poloxamer Mixtures as a Mucoadhesive Gel Base," Pharmaceutical Development and Technology, Vol. 16, No. 6, 2011, pp. 627-636. doi:10.3109/10837450.2010.508074

[8] R. Gurny, J. M. Meyer and N. A. Peppas, "Bioadhesive Intraoral Release Systems: Design, Testing and Analysis," Biomaterials, Vol. 5, No. 6, 1984, pp. 336-340. doi:10.1016/0142-9612(84)90031-0

[9] R. Masteikova, Z. Chalupova and Z. Sklubalova, "Stimuli Sensitive Hydrogels in Controlled and Sustained Drug Delivery," Medicina, Vol. 39, No. 2, 2003, pp. 19-24.

[10] M. Morishita, J. M. Barichello, K. Takayama, Y. Chiba, S. Tokiwa and T. Nagai, "Pluronic F-127 Gels Incorporating Highly Purified Unsaturated Fatty Acids for Buccal Delivery of İnülin," International Journal of Pharmaceutics, Vol. 212, No. 2, 2001, pp. 289-293. doi:10.1016/S0378-5173(00)00615-3

[11] D. S. Jones, A. F. Brown and A. D. Woolfson, "Solute and Solvent Effects on the Thermorheological Properties of Poly(oxyethylene)-poly(oxypropylene) Block Copolymers: İmplications for Pharmaceutical Dosage form Design," Journal of Applied Polymer Science, Vol. 87, No. 6, 2003, pp. 1016-1026. doi:10.1002/app.11534

[12] P. Alexandiridis and T. A. Hatton, "Poly(ethylene oxide)poly(propylene oxide)-poly(ethylene oxide) Block Copolymer Surfactants in Aqueous Solutions and İnterfaces: Thermodynamics, Structure, Dynamics and Modeling," Colloids and Surfaces A: Physicochemical and Engineering Aspects, Vol. 96, No. 1-2, 1995, pp. 1-46. doi:10.1016/0927-7757(94)03028-X

[13] A. V. Kabanov, E. V. Batrakova and V. Y. Alakhov, "Pluronic ${ }^{\circledR}$ Block Copolymers as Novel Polymer Therapeutics for Drug and Gene Delivery," Journal of Controlled Release, Vol. 82, No. 2-3, 2002, pp. 521-533. doi:10.1016/S0168-3659(02)00009-3

[14] L. Wang and X. Tang, "A Novel Ketoconazole Bio-Adhesive Effervescent Tablet for Vaginal Delivery: Design, in Vitro and in Vivo Evaluation," International Journal of Pharmaceutics, Vol. 350, No. 1-2, 2008, pp. 181-187. doi:10.1016/j.ijpharm.2007.08.042

[15] B. R. Sudeendra, H. Umme, R. K. Gupta and H. G.
Shivakumar, "Development and Characterization of Bioadhesive Vaginal Films of Clotrimazole for Vaginal Candidiasis," Acta Pharmaceutica Sciencia, Vol. 52, 2010, pp. 417-426.

[16] http://www.dow.com/dowexcipients/products/methocel.ht $\mathrm{m}$

[17] H. Choi, J. H. Jung, J. M. Ryu, S. J. Yoon, Y. K. Oh and C. K. Kim, "Development of in-Situ Gelling and Mucoadhesive Acetaminophen Liquid Suppository," International Journal of Pharmaceutics, Vol. 165, No. 4, 1998 , pp. 33-44. doi:10.1016/S0378-5173(97)00386-4

[18] J. Y. Chang, Y. K. Oh, H. Choi, Y. B. Kim and C. K. Kim, "Rheological Evaluation of Thermosensitive and Mucoadhesive Vaginal Gels in Physiological Conditions," International Journal of Pharmaceutics, Vol. 24, No. 1, 2002, pp. 155-163. doi:10.1016/S0378-5173(02)00232-6

[19] D. S. Jones, A. D. Woolfson, J. Djokic and W. A. Coulter, "Development and Mechanical Characterisation of Bioadhesive Semi-Solid, Polymeric Systems Containing Tetracycline for the Treatment of Periodontal Diseases," Pharmaceutical Research, Vol. 13, No. 11, 1996, pp. 1734-1738. doi:10.1023/A:1016413428473

[20] E. Baloglu, S. Y. Karavana, Z. Ay Senyigit, S. HilmiogluPolat, D. Y. Metin, O. Zekioglu, T. Guneri and D. S. Jones, "In-Situ gel Formulations of Econazole Nitrate: Preparation and in-Vitro and in-Vivo Evaluation," Journal of Pharmacy and Pharmacology, Vol. 63, No. 10, 2011, pp. 1274-1282. doi:10.1111/j.2042-7158.2011.01315.x

[21] D. S. Jones, A. D. Woolfson and A. F. Brown, "Design, Characterisation and Preliminary Clinical Evaluation of a Novel Mucoadhesive Topical Formulation Containing Tetracycline for the Treatment of Periodontal Disease," Journal of Controlled Release, Vol. 67, No. 2, 2000, pp. 357-368. doi:10.1016/S0168-3659(00)00231-5

[22] V. Burckbuchler, G. Mekhloufi, A. Paillard Giteau, J. L. Grossiord, S. Huille and F. Agnely, "Rheological and Syringeability Properties of Highly Concentrated Human Polyclonal Immunoglobulin Solutions," European Journal of Pharmaceutics and Biopharmaceutics, Vol. 76, No. 3, 2010, pp. 351-356. doi:10.1016/j.ejpb.2010.08.002

[23] D. S. Jones, A. D. Woolfson and A. F. Brown, "Textural, Analysis and Flow Rheometry of Novel, Bioadhesive Antimicrobial Oral Gels," Pharmaceutical Research, Vol. 14, No. 4, 1997, pp. 450-457. doi:10.1023/A:1012091231023

[24] D. S. Jones, A. D. Woolfson and A. F. Brown, "Textural, Viscoelastic and Mucoadhesive Properties of Pharmaceutical Gels Composed of Cellulose Polymers," International Journal of Pharmaceutics, Vol. 151, No. 2, 1997, pp. 223-233. doi:10.1016/S0378-5173(97)04904-1

[25] G. P. Andrews, S. P. Gorman and D. S. Jones, "Rheological Characterisation of Primary and Binary Interactive Bioadhesive Gels Composed of Cellulose Derivatives Designed as Ophthalmic Viscosurgical Devices," Biomaterials, Vol. 26, No. 5, 2005, pp. 571-580. doi:10.1016/j.biomaterials.2004.02.062

[26] G. P. Andrews and D. S. Jones, "Rheological Characterization of Bioadhesive Binary Polymeric Systems Designed as Platforms for Drug Delivery İmplants," Biomacro- 
molecules, Vol. 7, No. 3, 2006, pp. 899-906. doi:10.1021/bm050620y

[27] J. Neves, H. Amaral Maria and F. Bahia Maria, "Performance of an in Vitro Mucoadhesion Testing Method for Vaginal Semisolids: Influence of Different Testing Conditions and İnstrumental Parameters," European Journal of Pharmaceutics and Biopharmaceutics, Vol. 69, No. 2, 2008, pp. 622-632. doi:10.1016/j.ejpb.2007.12.007

[28] A. Kramaric, A. Resman, B. Kofler, J. Zmitek, "Thermoreversible Gel as a Liquid Pharmaceutical Carrier for a Galenic Formulation," European Patent No. 0551626. 1992.

[29] S. Miyazaki, F. Suisha, N. Kawasaki, M. Shirakawa, K. Yamatoya and D. Attwood, "Thermally Reversible Xyloglucan Gels as Vehicles for Rectal Drug Delivery," Journal of Controlled Release, Vol. 56, No. 1-3, 1998, pp. 75-83. doi:10.1016/S0168-3659(98)00079-0

[30] K. Edsman, J. Carlfors and R. Petersson, "Rheological Evaluation of Poloxamer as an in Situ Gel For Ophthalmic Use," European Journal of Pharmaceutical Sciences, Vol. 6, No. 1, 1998, pp. 105-112. doi:10.1016/S0928-0987(97)00075-4

[31] J. Xuan, P. Balakrishnan, D. H. Oh, W. H. Yeo, S. M. Park and C. S. Yong, "Choi HG. Rheological Characterization and in Vivo Evaluation of Thermosensitive Poloxamer-Based Hydrogel for İntramuscular Injection of Piroxicam," International Journal of Pharmaceutics, Vol. 395 , No. 1-2, 2010, pp. 317-323. doi:10.1016/i.ijpharm.2010.05.042

[32] J. Y. Chang, Y. K. Oh, H. S. Kong, E. J. Kim, D. D. Jang, K. T. Nam and C. K. Kim, "Prolonged Antifungal Effects of Clotrimazole-Containing Mucoadhesive Thermosensitive Gels on Vaginitis," Journal of Controlled Release, Vol. 82, No. 1, 2002, pp. 39-50. doi:10.1016/S0168-3659(02)00086-X

[33] D. S. Jones, A. D. Woolfson and J. Dkokic, "Texture Profile Analysis of Bioadhesive Polymeric Semisolids: Mechanical Characterization and Investigation of Interactions between Formulation Components," Journal of Applied Polymer Science, Vol. 61, No. 12, 1996, pp. 2229-
2234.

doi:10.1002/(SICI)1097-4628(19960919)61:12<2229::AI D-APP24>3.0.CO;2-0

[34] M. L. Bruschi, D. S. Jones, H. Panzeri, M. P. Gremiao, O. Freitas and E. H. Lara, "Semisolid Systems Containing Propolis for the Treatment of Periodontal Disease: In Vitro Release Kinetics, Syringeability, Rheological, Textural, and Mucoadhesive Properties," Journal of Pharmaceutical Sciences, Vol. 96, No. 8, 2007, pp. 2074-2089. doi:10.1002/jps.20843

[35] D. S. Jones, M. S. Lawlor and A. D. Woolfson, "Rheological and Mucoadhesive Characterization of Polymeric Systems Composed of Poly(methylvinylether-co-maleic anhydride) and Poly(vinylpyrrolidone), Designed as Platforms for Topical Drug Delivery," Journal of Pharmaceutical Sciences, Vol. 92, No. 5, 2003, pp. 995-1007. doi:10.1002/jps.10357

[36] E. Cevher, D. Sensoy, M. A. M. Taha and A. Araman, "Effect of Thiolated Polymers to Textural and Muco-Adhesive Properties of Vaginal Gel Formulations Prepared with Polycarbophil and Chitosan," AAPS Pharm-SciTech, Vol. 9, No. 3, 2008, pp. 953-965. doi:10.1208/s12249-008-9132-y

[37] C. S. Yong, J. S. Choi, Q. Z. Quan, J. D. Rhee, C. K. Kim, S. J. Lim, P. S. Oh and H. G. Choi, "Effect of Sodium Chloride on the Gelation Tem Perature, Gel Strength and Bioadhesive Force of Poloxamer Gels Containing Diclofenac Sodium," International Journal of Pharmaceutics, Vol. 226, No. 1-2, 2001, pp. 195-205. doi:10.1016/S0378-5173(01)00809-2

[38] S. B. Ross-Murphy, "Physical Gelation of Synthetic and Biological Macromolecules," In: D. DeRossi, et al., Eds., Polyer Gels: Fundamentals and Biomedical Application, Plenum Press, NewYork, 1991, pp. 21-39.

[39] S. Ikeda and K. Nishinari, “'Weak Gel'-Type Rheological Properties of Aqueous Dispersions of Nonaggregated KCarragenan Helices," Journal of Agricultural and Food Chemistry, Vol. 49, No. 9, 2001, pp. 4436-4441. doi:10.1021/jf0103065 